\title{
Case Report: Mandibular Second Premolar, A Morphological Ingruity
}

\author{
Dr. Mridusmita Mukherjee ${ }^{1}$, Dr. Antara Bhattacharyya ${ }^{2}$ \\ 1. (MDS In Conservative Dentistry And Endodontics ,Regional Dental College/ Srimanta Sankaradeva \\ University Of Health Sciences, India) \\ ${ }_{2}^{2}$ (BDS,M.R.Ambedkar Dental College And Hospital/Rajiv Gandhi University Of Health Sciences, India)
}

\begin{abstract}
The root canal is a complex system of finely tuned and synchronized small tributaries present along the body of tooth dentine. Therefore, knowledge of pulp anatomy is essential for endodontic treatment success, as lack of sound knowledge of the pulp anatomy can contribute to treatment failure. With the advancement of technological aids and numerous research have laid the foundation of multi rooted teeth or canals as the rule rather than exception. As such, bifurcating canals, multiple foramina, fins, deltas, loops, cul-de-sacs, $C$-shaped canals and accessory canals are commonly encountered in most teeth. So, accurate diagnosis followed by location, cleaning and shaping and finally obturation of such variations of canals is important as it determines the prospect of success of endodontic therapy.
\end{abstract}

Keywords: cleaning, morphology, pulp anatomy, root canals, shaping.

\section{Introduction}

Past literature describing pulp-chamber anatomy has been very general and undefined in determining the location and number of root canal orifice. The anatomic complexities of the roots and canals produces a challenging task in cleaning, shaping and obturation. Such variations can sometimes be quite difficult to detect, clean and fill. If tissue is trapped inside one of them, it can become infected and thereby the treatment may fail. Thus, successful endodontics revolves around knowledge, respect and appreciation for root canal anatomy and careful, thoughtful, meticulously performed cleaning and shaping procedures. Hence, it becomes imperative for a clinician to fully understand this system. As what one cannot see, cannot negotiate and what cannot be negotiated, cannot be prepared.

Mandibular lower premolars usually have a single root and a canal but changes in root canal configuration is not uncommon. Slowey ${ }^{[1]}$ indicated that the distributions of the numbers of roots and canals vary greatly in the literature which makes them difficult to clean and shape. Variation in root canal morphology was suggested as the most likely reason for the high frequency of endodontic flare-ups and failures ${ }^{[2]}$. The root canal morphologies of the mandibular premolars have been reported based on studies of various population. Zillich ${ }^{[3]}$ and Dowsen revealed that second or third canals are present in at least $12.1 \%$ of second mandibular premolars. Vertucci ${ }^{[4]}$ found two canals in $2.5 \%$ of those teeth. In France, Geider ${ }^{[5]}$ et al. observed $13.4 \%$ of population have two canals whereas in Turkey, Sert ${ }^{[6]}$ and Bayirli found $29 \%$ have two canals. Such observations have been reported based on studies of various population groups including Chinese, Turkish, American, Mexican, and African American populations.

\section{Clinical and radiographic perspectives}

Below are some of the guidelines that may be useful to enhance the interpretation of periapical radiographic images in detection of morphological oddity of root canals.

1. Adequate knowledge of normal and unusual anatomy before attempting endodontic treatment can serve as an important tool in diagnosis and success in clinical practice. Clinicians should be aware of the occurrence of variations of root canal morphology e.g, three-rooted or a fourth distal canal or a middle mesial canal in mandibular molars, double canalled mandibular incisors, double-rooted lower first and second premolars, three-rooted/-canalled maxillary premolars, four-rooted maxillary molars etc.

2. One should also keep in mind the anatomic considerations surrounding the teeth to be treated such as (a) the incisive foramen, (b) the mental foramen and its neurovascular bundle, (c) the maxillary sinus (d) the mandibular canal and its neurovascular bundle. Sound knowledge of such structures can help to avoid potential injury of these structures during orthograde and retrograde endodontic procedures.

3. Radiographic considerations:

a) preoperative radiographs with more than one horizontal projection can help to interpret the bucco-lingual dimensions of the tooth and its surrounding structures. The mental foramen is visible on $75 \%$ of the horizontal periapical radiographs. This radiographic appearance may result in a misdiagnosis of a radiolucent lesion in the apical area of mandibular premolar teeth. 
b)A general guideline is that if the mid-root image diameter appears equal or greater than the crown image diameter, then the tooth most likely has a variation in root canal configuration (Miyoshi et al,1977).

c) Yoshioka et al. ${ }^{[13]}$ have indicated that sudden narrowing of the canal system on a parallel radiograph suggests canal system multiplicity.

d)Martinez-Lozano et al. ${ }^{[14]}$ have suggested a $40^{\circ}$ mesial angulation of the X-ray beam to identify additional canals.

e) Using a "film holder" can access appropriate dimensions of the tooth and can assist in more accurate comparison during assessment of the degree of healing of a peri-radicular lesion if any. A "break point" in the outline of any root canal is a landmark for the presence of multiple canals which can be observed bilaterally.

f) The presence of additional canal should be suspected whenever an instrument demonstrates an eccentric direction on deeper penetration into the canal, termed "directional control" as reported by Green ${ }^{[15]}(1973)$, or if the working length file appears off center in the radiograph.

g) The application of contrast medium (such as Hypaque and Iohexol) inside the root canals has been reported to enhance the radiographic interpretation of the root canal morphology and can be tried.

h)Using an even light source and blocking out peripheral light are also advantageous.

\section{Case report}

A 45-year-old female patient was referred to our endodontic department for management of lower left second premolar as a part of treatment management for fixed prosthesis. However, the patient gave a history of sensitivity to cold for the past three months and intermittent pain which was aggravated on lying down. Clinically, the tooth was restored with amalgam and the restoration was found to be chipped out. There was no first and second molars in that quadrant, hence retaining the tooth was very critical for prosthetic rehabilitation of the patient. On radiographic examination preoperative (fig 1), the periodontal ligament outline suggested a rare anatomical feature and hence a second radiograph with a more mesial angulation was taken for a clear view (tube shift technique). Two roots were found and were distinguished as buccal and lingual based on the clark's SLOB rule, which states that if an object moves from its reference point towards the distal side, while the tube is shifted mesially, then the object lies on the buccal aspect and viceversa. After coronal disassembly and access opening under rubber dam isolation, pulp chamber was negotiated and access was refined in a bucco-lingual direction as per the pre-operative radiograph. Orifices were found much below than the conventional location. Following that, patency was achieved by a no 8 and $10 \mathrm{k}$ file. To distinguish between the two roots and canals, two separate k-file were inserted into each of the canals. After confirmation, working length was determined and chemo- mechanical preparation was done using Protaper next X3 using a copious irrigation of 3\% $\mathrm{NaOCl}$, saline, EDTA solution. The obturation was performed using standardized gutta-percha and AH plus sealer by means of lateral condensation in a single visit. Post obturation radiograph was taken where two separate roots can be well appreciated. The coronal half was restored with composite .Patient was asymptomatic following the procedure and radiographs showed healing of the periradicular region.
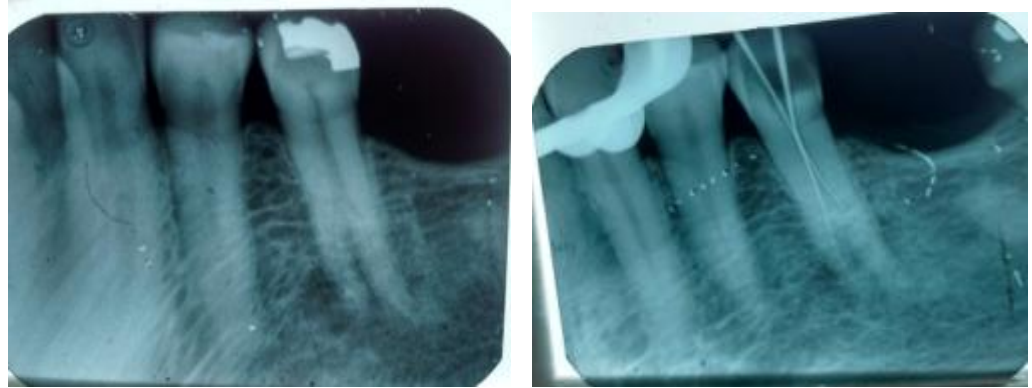

Fig 1: preoperative IOPA radiograph Fig 2: working length IOPA

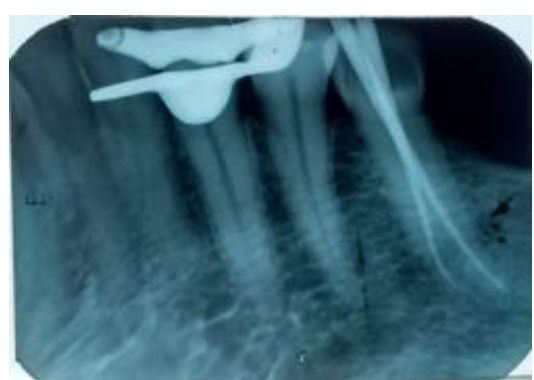

Fig 3: master cone IOPA

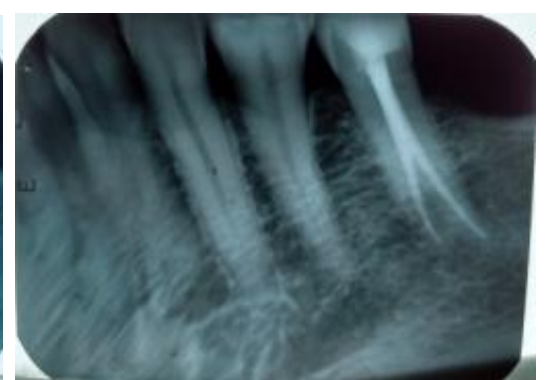

fig 4: post obturation IOPA 


\section{Discussion}

The presence of extra roots or canals in mandibular premolars is undoubtedly an endodontic challenge The mandibular premolars usually have one root with one canal ${ }^{[7,8]}$. But, it accounts for high failure rate in endodontic treatment owing to flare ups or missed canals owing to anatomic complexities ${ }^{[7]}$. Factors such as ethnicity, age, gender and study design happen to influence such complexities which has lead to a wide range of variations as per literature review. Vertucci (1984) determined an incidence of $3 \%$ of a second canal in mandibular second premolar and that of an apical delta in 9\%. Prevalence of lateral canals was found to be $48 \%$ and the ratio of apical foramina was $84 \%$ for these teeth. Caliskan et al. (1995) confronted a single canal in $94 \%$ of second premolars and reported $39 \%$ of these teeth had lateral canals, respectively. Sert et al. reported a prevalence of $71 \%$ of a single canal and $14 \%$ of lateral canals in the second premolars. Trope et al. ${ }^{[10]}$ and Sabala et al. ${ }^{[1]}$ reported their in vivo results on root number and internal canal morphology by the number of patients rather than by the total number of teeth. $5.2 \%$ and $4.4 \%$ of the patients showed the prevalence of two or more canals and occurrence of $\mathrm{C}$-shaped canals in $2 \%$ of population ${ }^{[12]}$.

\section{Conclusion}

Endodontic treatment in mandibular second premolars can be challenging at times. One may find it difficult to treat complicated endodontic anatomy like the second mandibular premolar presented in this article, but understanding the canal anatomy and producing a good mental map is a key to successful endodontic therapy in any tooth.

\section{References}

[1]. Slowey RR. Root canal anatomy. Road map to successful endodontics. Dent Clin North Am 1979;23:555-73

[2]. B.M. Clegborn, W.H. Christie, C.C.S. Dong .The root and root canal morphology of the human mandibular second premolar: a literature review .J Endod, 33 (9) (2007), pp. R.

[3]. Zillich, J. Dowson .Root canal morphology of mandibular first and second premolars .Oral Surg Oral Med Oral Pathol, 36 (5) (1973), pp. 738-744.1031-1037

[4]. F.J. Vertucci .Root canal morphology of mandibular premolars .J Am Dent Assoc, 97 (1978), pp. 47-50

[5]. P. Geider, C. Perrin, M. Fontaine,Endodontic anatomy of lower premolars: apropos of 669 cases, J Odontol Conserv, 10 (1989), pp. $11-15$

[6]. S. Sert, G.S. Bayirli. Evaluation of the root canal configurations of the mandibular and maxillary permanent teeth by gender in the Turkish population J Endod, 30 (2004), pp. 391-398

[7]. Ingle J, Bakland L. Text book of Endodontics. $5^{\text {th }}$ ed. Hamilton: BC Decker; 2002

[8]. Ash M, Nelson S. Wheeler's Dental Anatomy, Physiology and Occlusion. ${ }^{\text {th }}$ ed. Philadelphia: Saunders; 2003.

[9]. Sert S, Aslanalp V, Tanalp J. Investigation of the root canal configurations of mandibular permanent teeth in the Turkish population. Int Endod J 2004;37:494-9

[10]. Trope M, Elfenbein L, Tronstad L. Mandibular premolars with more than one root canal in different race groups. J Endod 1986;12:343-5.

[11]. Sabala CL, Benenati FW, Neas BR. Bilateral root or root canal aberrations in a dental school patient population. J Endod 1994;20:38-42

[12]. Varrela J, Townsend G, Alvesalo L. Tooth crown size in human females with 45, X/46, XX chromosomes. Arch Oral Biol 1988;33:291-4.

[13]. Yoshioka T, Villegas JC, Kobayashi C, Suda H. Radiographic evaluation of root canal multiplicity in mandibular first premolars. J Endod 2004;30:73-4

[14]. Martinez-lozano MA, Forner-Navarro L, Sanchez-Cortes JL. Analysis of radiologic factors in determining premolar root canal systems. Oral Surg Oral Med Oral Pathol Oral Radiol Endod 1999;88:719-22

[15]. Rodig T, Hulsmann M. Diagnosis and root canal treatment of a mandibular second premolar with three root canals. Int Endod J 2003;36:912-9. 